
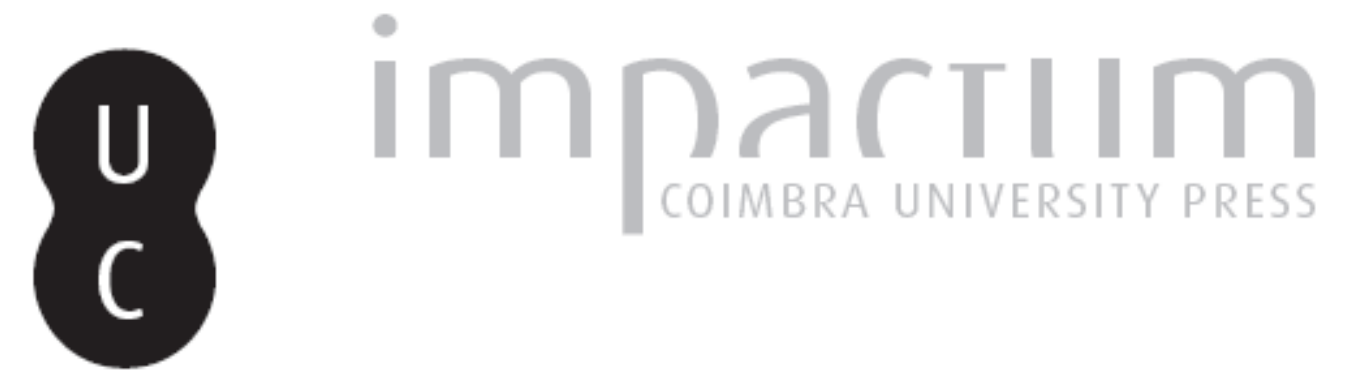

\title{
Primavera e Inverno da Filologia Românica
}

Autor(es): $\quad$ Silva, Vítor Aguiar e

Publicado por: Faculdade de Letras da Universidade de Coimbra

URL persistente:

URI:http://hdl.handle.net/10316.2/32451

DOI:

DOI:http://dx.doi.org/10.14195/0870-4112_9_8

Accessed : $\quad$ 26-Apr-2023 06:03:55

A navegação consulta e descarregamento dos títulos inseridos nas Bibliotecas Digitais UC Digitalis, UC Pombalina e UC Impactum, pressupõem a aceitação plena e sem reservas dos Termos e Condições de Uso destas Bibliotecas Digitais, disponíveis em https://digitalis.uc.pt/pt-pt/termos.

Conforme exposto nos referidos Termos e Condições de Uso, o descarregamento de títulos de acesso restrito requer uma licença válida de autorização devendo o utilizador aceder ao(s) documento(s) a partir de um endereço de IP da instituição detentora da supramencionada licença.

Ao utilizador é apenas permitido o descarregamento para uso pessoal, pelo que o emprego do(s) título(s) descarregado(s) para outro fim, designadamente comercial, carece de autorização do respetivo autor ou editor da obra.

Na medida em que todas as obras da UC Digitalis se encontram protegidas pelo Código do Direito de Autor e Direitos Conexos e demais legislação aplicável, toda a cópia, parcial ou total, deste documento, nos casos em que é legalmente admitida, deverá conter ou fazer-se acompanhar por este aviso.

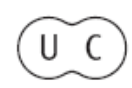



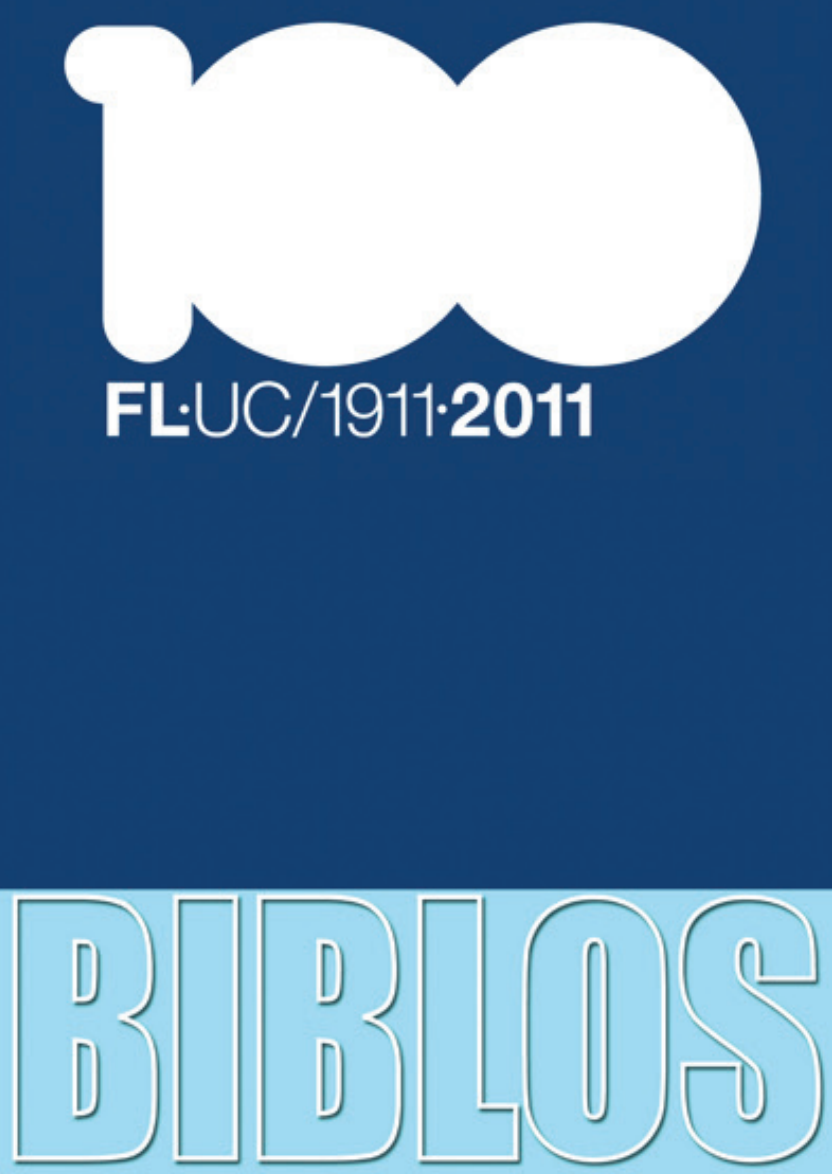

REVISTA DA FACULDADE DE LETRAS UNIVERSIDADE DE COIMBRA 
Vítor Aguiar e Silva

Universidade do Minho

\title{
PRIMAVERA E INVERNO DA FILOLOGIA ROMÂNICA
}

\section{Resumo}

A genealogia dos saberes disciplinares professados nas Universidades e a sua relevância para a história dos paradigmas científicos. A emergência no epistema moderno de uma nova «positividade filológica» (Foucault) e a constituição das filologias modernas, segundo o modelo da filologia clássica. A filologia oitocentista e as suas hipotecas ideológicas relativamente ao nacionalismo romântico e ao colonialismo europeu. O método histórico-comparativo de Franz Bopp e a criação da filologia românica. O desenvolvimento científico e a irradiação cultural da filologia românica nas Universidades alemãs e nas Universidades europeias. A institucionalização da filologia românica na Faculdade de Letras da Universidade de Coimbra. Carolina Michaëlis de Vasconcelos e o seu conceito de filologia como Wortphilologie. Causas do declínio da filologia. A autonomização científico-disciplinar da linguística. A necessidade do "regresso" da filologia, no quadro de uma nova interdisciplinaridade entre os estudos linguísticos e os estudos literários. A filologia e as suas articulações com a linguística, a hermenêutica, a história literária, a teoria da literatura e a literatura comparada.

Palavras-Chave: Genealogia dos paradigmas científicos, Filologia, Filologia românica, Linguística, Ecdótica, Hermenêutica.

\begin{abstract}
The genealogy of disciplinary knowledge taught in the universities and its relevance to the history of scientific paradigms. The rise of a new "positivity of philology" (Foucault) within the modern episteme, and the constitution of modern philologies after the model of classical philology. Nineteenthcentury philology and its ideological connections to Romantic nationalism and European colonialism. The comparative historical method of Franz Bopp and the establishment of Romanic Philology. Academic development and cultural dissemination of Romanic Philology at German universities and European universities. The institutionalization of Romanic Philology at the Faculty of Arts and Humanities, University of Coimbra. Carolina Michaëlis
\end{abstract}


de Vasconcelos and her concept of philology as Wortphilologie. Causes for the decline of philology. The development of linguistics as an autonomous academic discipline. The need for the "return" of philology in the framework of a new interdisciplinary approach involving linguistic studies and literary studies. Philology and its linkages with linguistics, hermeneutics, literary history, theory of literature and comparative literature.

Keywords: Genealogy of scientific paradigms, Philology, Romanic Philology, Linguistics, Textual Criticism, Hermeneutics. 
Agradeço o convite que o Senhor Director da Faculdade de Letras, Doutor Carlos Ascenso André, teve a amabilidade de me endereçar para proferir esta conferência. Proporcionou-me assim a oportunidade de participar presencialmente nas comemorações do centenário da criação desta Faculdade, a Escola onde obtive todos os meus graus e títulos académicos, onde estudei e ensinei durante décadas e que para sempre será, na minha memória e nos meus afectos, a minha Casa universitária.

Nas singelas palavras que vou dizer, não me ative fielmente à letra do tema que o Senhor Director da Faculdade me propôs, mas o espírito das minhas análises e reflexões, assim o espero, não será dissonante ou arredio em relação ao tema proposto.

O estudo da constituição, do desenvolvimento e das transformações dos saberes disciplinares professados nas Universidades, no âmbito das chamadas ciências humanas e sociais, é um domínio do conhecimento que me fascina desde há muitos anos. Como e porquê nas escolas universitárias nascem, florescem e se extinguem ou se transformam as disciplinas? Como e porquê se instituem determinados paradigmas no ensino e na investigação? Como e porquê ocorrem as rupturas, as alterações e as descontinuidades desses paradigmas? Como e porquê se retomam, resgatam e actualizam orientações epistemológicas e disciplinares caídas em declínio ou mesmo em descrédito, originando as denominações de saberes prefixadas com neo -? Quais as relações genealógicas das disciplinas universitárias e das suas formações discursivas com a enciclopédia científica e filosófica de cada época e com a doxa, os ideais, as necessidades e os constrangimentos das sociedades nos sucessivos tempos históricos? Parafraseando a célebre afirmação de Paul Valéry, segundo a qual sabemos, depois de ominosos acontecimentos da história contemporânea da Europa, que a própria civilização é mortal, direi que hoje sabemos, décadas após a hegemonia das vulgatas positivistas - este plural é relevante -, que as disciplinas científicas são transientes, tanto intrínseca como extrinsecamente, podendo tão-só configurar-se como estáticas ou mesmo definitivas por inércia institucional ou por dogmática rigidez mental dos responsáveis pelo seu ensino e pela sua reprodução.

Entender as disciplinas como transientes equivale à necessidade de escrutinar a sua genealogia, no específico sentido foucaultiano do termo, 
isto é, de examinar as relações mútuas que existem entre os objectivos, os conceitos, os métodos e as verdades dos sistemas de conhecimento, em particular das chamadas ciências humanas, e as modalidades de poder, maxime de poder político, e implica a necessidade de continuamente avaliar a sua capacidade de adaptação dinâmica no tempo futuro, em novos contextos epistémicos, institucionais, sociais, culturais e económicos. A história de uma ciência apresenta sempre uma face solar e uma face nocturna: é uma eflorescência de conhecimentos novos e pregnantes e é um desolado cemitério de teorias, práticas e celebridades recobertas de esquecimento mais ou menos espesso. Os museus das ciências são o espaço ambivalente onde coexistem os signos de triunfo e os padrões de perdurabilidade e as marcas de declínio e as inscrições tanatográficas das disciplinas científicas.

De certo modo, vou convidar os que me escutam a fazer uma breve visita ao museu imaginário da Filologia e em particular da Filologia Românica - uma visita guiada pela memória do aluno que, há 54 anos, frequentou nesta Faculdade a disciplina de «Introdução aos Estudos Linguísticos», guiado pela mão sabedora, metódica e exigente do Doutor Manuel de Paiva Boléo, um Mestre pedagogicamente exemplar, coadjuvado nas aulas práticas pelo Doutor Vincenzo Cuocco, docente de escassa simpatia humana, mas detentor de múltiplos e arqui-raros conhecimentos linguísticos.

Nesse ano de 1957, quando os Cursos de Licenciatura desta Faculdade foram refundados científica e pedagogicamente pela chamada «Reforma Leite Pinto» (Decreto n. ${ }^{\circ} 44.341$, de 30 de Outubro de 1957), duas disciplinas me desvelaram horizontes científicos e culturais novos: «História da Cultura Clássica», regida magistralmente pela minha querida Mestra, Doutora Maria Helena da Rocha Pereira, e «Introdução aos Estudos Linguísticos», que me proporcionou uma informação sólida sobre o desenvolvimento dos estudos filológicos e linguísticos e uma reflexão aprofundada sobre alguns domínios da filosofia da linguagem (recordo-me bem de que na prova oral do exame final, da qual não havia dispensa, falei longamente das teorias de Karl Vossler sobre positivismo e idealismo na ciência da linguagem, sendo a obra do mestre alemão, de consulta obrigatória, lida na tradução espanhola de 1929). A também recém criada disciplina de «Teoria da Literatura» pouco trazia de novo ao aluno que no Liceu já lera e relera os Fundamentos da Interpretação e da Análise Literária, naquela 1. ${ }^{a}$ 
edição de 1948 com a sintaxe germanicamente contorcida, que depois a mão de Paulo Quintela havia de urbanizar, mas em cujas páginas esplendiam como jóias fúlgidas alguns poemas de Camilo Pessanha e de Mário de Sá-Carneiro, autores ausentes das antologias de Português desses anos da década de cinquenta.

Nos primeiros decénios do século XX, constituíram-se na Europa saberes novos que, em grande parte, consubstanciavam o projecto da scienza nuova, cujas necessidade e legitimidade tinham sido advogadas por Giambattista Vico (1668-1744) na sua obra magna Principi di scienza nuova, primeiramente publicada em 1725 e de que a edição definitiva data do ano da morte do pensador napolitano. À ciência cartesiana, de fundamentação lógico-matemática, contrapôs Vico a ciência nova que tinha como objecto as criações históricas do próprio homem, desde a linguagem, a poesia e o mito até à religião e ao direito. $\mathrm{O}$ princípio gnosiológico verum ipsum factum - primeiramente exposto no trabalho viquiano De antiquissima italorum sapientia (1710) - garantia que o homem podia conhecer o que ele próprio criara, o mundo das obras do espírito e das instituições sociais, il mondo delle nazioni, por oposição ao mundo físico, il mondo della natura.

A Aufklärung setecentista tinha contribuído já para o desenvolvimento da «ciência nova», como demonstrou, entre outros investigadores, Georges Gusdorf na sua obra L'avènement des sciences humaines au siècle des Lumières (Paris,1973), mas foi com o Romantismo, sobretudo com o Romantismo alemão, que as «ciências do espírito» (Geisteswissenchaften) e as «ciências humanas» alcançaram o estatuto de saberes autónomos, configuraram o paradigma moderno do conhecimento e obtiveram a sua legitimação académica graças à sua progressiva institucionalização nas Universidades e noutras instituições de ensino superior (v.g., no Collège de France). No capítulo VIII de Les mots et les choses. Une archéologie des sciences humaines (1966), Michel Foucault desenhou a cartografia das novas empiricidades - configuradas, em grande medida, como objectos epistémicos - e das correlativas ciências que, nas duas primeiras décadas do século XIX, assinalam «o limiar da nossa modernidade». As novas empiricidades são a Vida, o Trabalho e a Linguagem e as novas ciências dominantes são emblematicamente representadas por Georges Cuvier (1769-1832), David Ricardo (1772-1823) e Franz Bopp (1791-1867). 
Cuvier criou a anatomia comparada, elaborou a primeira classificação científica dos animais, estabeleceu os princípios da correlação das formas e dos órgãos, fundou a paleontologia, ciência que estuda os fósseis vegetais e animais, reconstituindo os organismos originários a partir de fragmentos e indícios subsistentes. Cuvier exerceu uma influência decisiva, numa perspectiva interdisciplinar, na adopção do método comparativo como instrumento da descrição morfológica e da análise genealógica de numerosos fenómenos biológicos, sociais e culturais, contribuindo, conjuntamente com outros pensadores e cientistas, desde Goethe a Schelling, para substituir o modelo fisicista e mecanicista do conhecimento e da inteligibilidade do mundo por um modelo organicista e biológico.

Ricardo analisou a relevância do trabalho na actividade económica, pondo em evidência como os custos de produção influenciam os preços das mercadorias e como o trabalho decorre da necessidade de o homem lutar contra a raridade dos bens de consumo, contra a subida dos preços e contra o empobrecimento progressivo das sociedades. O homo oeconomicus de Ricardo é refém de uma visão antropológica pessimista que culmina na ameaça da imobilização da História.

Franz Bopp, sob a influência da anatomia comparada de Cuvier e, mais especificamente, sob a influência de Friedrich Schlegel, a quem se ficou a dever o termo e o conceito de gramática comparada, ${ }^{1}$ publicou em 1816, apenas com 25 anos de idade, a sua inovadora obra Sobre o sistema de conjugação da língua sânscrita em comparação com o das línguas grega, latina, persa e germânica, na qual se propôs efectuar a comparação rigorosamente sistemática das referidas línguas e descrever a sua anatomia, concebendo as línguas como organismos e mecanismos de que era necessário estudar as leis físicas, mecânicas e fisiológicas. Bopp distancia-se assim das concepções romântico-idealistas das línguas como criações do espírito humano e do espírito das nações, não

${ }^{1}$ Na sua obra Über die Sprache und Weisheit der Indier (Heidelberg, 1808), escreveu Friedrich Schlegel:«Mas o ponto decisivo,que deve esclarecer toda a questão, é a estrutura interna das línguas ou a gramática comparada, que nos oferecerá elementos totalmente novos para estabelecer a genealogia das línguas, de modo similar como a anatomia comparada faz luz sobre a mais antiga história natural» (texto reproduzido em Lia Formigari, La linguistica romantica, Torino, 1977, p. 164). 
hesitando Peter Schmitter em atribuir-lhe uma clara tendência para um «positivismo radical».2

Entre as novas disciplinas do epistema moderno mencionadas por Foucault, Franz Bopp representa a filologia, ou mais rigorosamente, para utilizar a expressão de Les mots et les choses, representa uma nova «positividade filológica». Com efeito, perguntar-se-á com razão, a filologia não existia desde há muitos séculos, desde a época helenística, tendo conhecido períodos de grande fulgor e prestígio como durante o Humanismo renascentista? No limiar da sua História da filologia clássica, Rudolf Pfeiffer formula a seguinte definição que será a directriz de toda a obra: «A filologia é a arte de compreender, explicar e restabelecer a tradição literária. Nasceu como disciplina intelectual independente no século III a.C., graças aos esforços dos poetas para conservar a herança literária, os "clássicos" e servir-se dela. Por conseguinte, a filologia surgiu, na realidade, como filologia "clássica"». ${ }^{3}$ Prudentemente, Pfeiffer marca com aspas os termos "clássicos" e "clássica", porque em ambos os casos o vocábulo "clássico" tem um uso anacrónico, difícil de evitar.

Em teoria e na prática, como assinalou Carolina Michaëlis de Vasconcelos, «até ao fim do século XVIII não houve outra filologia senão esta clássica». ${ }^{4}$ De facto, quer os filólogos do Renascimento italiano, quer os filólogos quinhentistas, seiscentistas e setecentistas dos Países Baixos, da França, da Península Ibérica e da Inglaterra, não cultivaram «outra filologia senão esta clássica». Em rigor histórico, porém, o termo e o conceito de filologia clássica foram refundados no início do século XIX, quando a «ciência da Antiguidade» (Altertumswissenschaft) concebida por Friedrich August Wolf (1759-1824) passou a ser denominada com frequência crescente como klassische Altertumswissenschaft e se configurou como disciplina autónoma, centrada no estudo da cultura grega, em conformidade com os princípios e os ideais do neo-helenismo difundido por Johann

${ }^{2}$ Peter Schmitter, «Le savoir romantique», Sylvain Auroux (dir.), Histoire des idées linguistiques. Tome 3. L’hégémonie du comparatisme, Liège, 2000, p. 69.

${ }^{3}$ Rudolf Pfeiffer, Historia de la filología clásica. I. Desde los comienzos hasta el final de la época helenística, Madrid, 1981, p. 25.

${ }^{4}$ Carolina Michaëlis de Vasconcelos, Lições de filologia portuguesa, Lisboa, s.d., p. 133. 
Joachim Winckelmann (1717-1768). A nova Universidade de Berlim, ideada e fundada (1809) pelo filósofo, filólogo e político Wilhelm von Humboldt (1777-1835), acolheu e desenvolveu a filologia clássica como área disciplinar central, com professores como o citado Friedrich August Wolf, célebre desde a publicação da sua obra Prolegomena ad Homerum (1795) e, a partir de 1811, com o jovem August Boeckh (1785-1867), a quem se ficou a dever a fundação, na nova Universidade, do Seminário de Filologia. A criação dos liceus humanísticos, escolas fundamentais para a educação dos jovens da burguesia prussiana, exigia docentes com a adequada formação universitária, garantida pelo exame pro facultate docendi, realizado perante um júri de professores universitários. Neste novo contexto escolar e profissional, a filologia clássica libertou-se da função ancilar ou subalterna que até então fora a sua no âmbito das Faculdades de Artes, nas quais proporcionava um ensino propedêutico aos alunos que se destinavam às Faculdades de Teologia, Leis e Medicina. A filologia clássica, ao mesmo tempo que consolidava o seu estatuto científico, graças em grande parte à criação dos Seminários e aos incentivos concedidos à investigação, tornava-se assim uma Brotwissenschaft, uma ciência que proporcionava "pão", figurando cronologicamente, na Alemanha, como a primeira das profissões modernas, solicitada pelo Estado a assegurar de modo dominante a formação (Bildung) das gerações jovens. Entre as estratégias e as conveniências do poder político e a produção e a transmissão do conhecimento estabeleceram-se assim articulações estruturais. O modelo prussiano de cooperação e articulação do ensino universitário com o ensino secundário, com o objectivo de formar um corpo docente cientificamente qualificado para os liceus, difundiu-se em toda a Europa e tornou-se a razão determinante do ensino filológico-humanístico proporcionado pelas Faculdades de Letras ou instituições universitárias de natureza similar.

O Romantismo representou, sob todos os pontos de vista, o triunfo dos "modernos" - lembre-se que o termo "antigos" foi equivalente, durante longo período de tempo, ao termo "clássicos" -, o que não significa que não tenha existido no Romantismo um relevante filão helénico, ou, talvez melhor, uma leitura romântica do legado helénico. O estudo e o conhecimento científico das línguas, das literaturas, das instituições religiosas, jurídicas e políticas, etc., das nações modernas foram corolários naturais do triunfo do Romantismo. 
Por outras palavras, era inevitável a constituição da(s) filologia(s) moderna(s). Ora a filologia clássica, em virtude da sua consistência científica, do seu rigor metodológico, da sua rica tradição cultural, do seu prestígio institucional e social, devia ser o modelo das filologias modernas, como já em 1797 aconselhava Friedrich Schlegel no fragmento n. ${ }^{\circ} 156$ da Filosofia da Filologia e como August Boeckh reconheceu inequivocamente na sua Encyklopädie und Methodenlehre der philologischen Wissenschaften, argumentando que a essência da filologia consiste na sua metodologia, aplicável a diversos objectos de estudo, tanto antigos como modernos. ${ }^{5}$ Esta relação de solidariedade científica e pedagógica entre as Humanidades clássicas e as Humanidades modernas foi afectada, porém, em diversos países, sobretudo desde o último quartel do século XIX, por dissenções e conflitos mútuos que, como já escrevi, representaram mais um episódio da «Querela dos Antigos e dos Modernos» e tiveram como efeito perverso o prejuízo de todas as Humanidades. ${ }^{6}$ As Universidades, ao arrepio da lógica da racionalidade científica e contra os seus proclamados ideais da procura livre e desinteressada do conhecimento, são frequentemente vulneráveis a conflitos de interesses corporativos e grupais que se concretizam na disputa sobre a ocupação de territórios disciplinares.

Sob o signo do historicismo romântico, ocorreram nas primeiras décadas do século XIX profundas e perduráveis transformações da filologia. A descoberta das afinidades genealógicas existentes entre o sânscrito, o grego e o latim, revelada em 1786 por Sir William Jones (1746-1794), juiz na cidade de Calcutá, numa comunicação apresentada à Asiatick Society, abriu novos horizontes à investigação filológica e linguística, com a aplicação do método histórico-comparativo que possibilitou reconstituir a família das línguas indo-europeias e reconstruir a perdida língua matricial. O modelo da paleontologia e da anatomia comparada dos vertebrados concebido por Cuvier demonstrou

5 A Enciclopédia de Boeckh foi publicada postumamente em 1877 e reeditada em 1886. É uma obra que recolhe as ideias de Boeckh expostas nas suas lições ao longo de muitos anos. Utilizo a tradução parcial italiana intitulada La filologia come scienza storica. Enciclopedia e metodologia delle scienze filologiche (Napoli, 1987). Sobre a constituição das filologias modernas, vide pp. 39-40.

${ }^{6}$ Veja-se o meu ensaio intitulado «Reflexões tempestivas sobre a crise das Humanidades», coligido no volume As Humanidades, os estudos culturais, o ensino da literatura e a política da língua portuguesa, Coimbra, 2010, pp.63-68. 
neste domínio de investigação as suas grandes potencialidades interdisciplinares. Friedrich Schlegel, ao publicar em 1808 a sua atrás mencionada obra Über die Sprache und Weisheit der Indier, caucionou com o seu prestígio filosófico e literário esta abertura do Ocidente ao Oriente e deu um impulso decisivo ao estudo das relações genealógicas entre as línguas indo-europeias, com base na análise da sua estrutura interna (innere Struktur), como acima ficou dito. Edward W. Said (1935-2003) demonstrou, na sua grande obra Orientalism (1978)), que a filologia viria a tornar-se, primeiro com Silvestre de Sacy (1758-1838) e sobretudo depois com Ernest Renan (1823-1892), um instrumento científico e ideológico de primeira importância na elaboração do orientalismo como formação discursiva, como visão cultural e como projecto e prática do colonialismo europeu.

O método histórico-comparativo, no âmbito indo-europeu, ficou estabelecido de modo rigorosamente sistemático com as já mencionadas investigações de Franz Bopp. As obras que configuram a arquitectura da filologia histórico-comparativa sucederam-se em curto período de tempo: em 1818, o linguista dinamarquês Rasmus Rask (1787-1832) publicou a sua obra sobre as relações entre as línguas escandinavas e germânicas e o grego, o latim e o arménio (obra já apresentada, porém, em 1814 à Academia dinamarquesa); em 1819, Jacob Grimm (1785-1863) deu a conhecer a sua Gramática alemã (Deutsche Grammatik) de que a 2. edição, acrescentada com centenas de páginas sobre a fonética, saiu à luz em 1822, com análises comparativas muito precisas, baseadas num riquíssimo corpus de materiais linguísticos pertencentes a muitos séculos de história, desde o gótico ao alemão contemporâneo; em 1821, François Raynouard (1761-1836) publicou como volume VI e último da sua vasta obra Choix des poésies originales des Troubadours (Paris, 1816-1821) uma Grammaire comparée des langues de l'Europe latine, na qual expõe e advoga a tese da existência, há mais de dez séculos, de uma língua, nascida do latim corrompido, que serviu de tipo comum às línguas da Europa latina e que conservou as suas formas primitivas num idioma ilustrado pelos poetas que foram denominados trovadores. Apesar das suas limitações metodológicas e das suas inconsistências históricas e linguísticas, em particular a sua ideia de que o francês, o italiano e o espanhol derivariam da «langue romane intermédiaire» que era a língua dos trovadores provençais - sendo por conseguinte línguas neoprovençais ... -, Raynouard abriu o caminho 
para a elaboração de um modelo linguístico ajustado à explicação da génese das línguas românicas, no qual a língua matricial deixou de ser a fantasmática «langue romane intermédiaire» para passar a ser o chamado latim vulgar. Alguma razão coube a Friedrich Diez quando consideou Raynouard como o fundador da filologia românica.

Finalmente, em 1836, Friedrich Diez (1794-1876), que já tinha consagrado diversos estudos à poesia e à língua dos trovadores da Provença, na senda dos trabalhos pioneiros de Raynouard, publicou o primeiro dos três volumes da sua Gramática das línguas românicas (Grammatik der romanischen Sprachen, 1836, 1838, 1843), obra que é o marco fundamental, em estrito rigor científico, da filologia românica. Em 1854, Diez culminava a sua grandiosa arquitectura disciplinar com a publicação do Etymologisches Wörterbuch der romanischen Sprachen, abrangendo as principais línguas românicas: o italiano, o romeno, o português,o espanhol, o provençal e o francês. O filólogo que iniciara a sua carreira docente na Universidade de Bonn, em 1822, como modesto leitor de «línguas e literaturas meridionais», ou seja, de italiano, espanhol e português - em 1830, ascenderá a uma cátedra de história da literatura alemã -, apesar de ter atraído sempre escassos alunos e de não ter sido um professor brilhante, tornou-se com as suas obras, com o seu exemplo de probidade, de clareza e de rigor científicos, o mestre respeitado dos grandes filólogos alemães e estrangeiros das gerações seguintes, quer tivessem sido seus alunos directos, como Gaston Paris (1839-1903), quer discípulos indirectos, como o autodidacta extraordinário que foi Graziadio Isaia Ascoli (1829-1907).

Até meados do século XIX, foram escassas as cátedras de Línguas Românicas criadas nas Universidades alemãs - Halle, 1833; Marburg, 1836; Tübingen, 1844 -, mas o seu número aumentou rapidamente depois de 1850 , em virtude tanto do prestígio científico e cultural da nova área disciplinar como da necessidade de formar professores de línguas estrangeiras para os liceus humanísticos. ${ }^{7}$ Progressivamente, a filologia românica conquistou um espaço institucional próprio no ensino superior de diversos países, desde a Itália e a França à Suíça,

${ }^{7}$ Veja-se a lista das cátedras e dos institutos de filologia românica criados depois de 1850 em Hans Ulrich Gumbrecht, «"Un Souffle d'Allemagne ayant passé": Friedrich Diez, Gaston Paris and the genesis of national philologies», Romance Philology, XL, 1 (1986), p. 32. 
à Espanha, a Portugal, etc. São criadas em diversos países revistas especializadas dedicadas à nova disciplina: a Revue des Langues Romanes, em 1870; os Romanischen Studien, em 1871; a Romania, em 1872; a Zeitschrift für romanische Philologie, em 1877; a Romanische Forschungen em 1883, etc. Sinais eloquentes de que a filologia românica se tornara uma ciência consolidada e prestigiosa são a publicação, nas duas últimas décadas do século XIX, de importantes obras de natureza enciclopédica como a Encyclopädie und Methodologie der romanischen Philologie (1884, 3 vols.) de Gustav Körting e sobretudo como o monumental Grundriss der romanischen Philologie (1888-1902, 2 vols.) dirigido por Gustav Gröber e com a colaboração dos mais qualificados especialistas nas áreas da linguística e da literatura. Wilhelm Meyer-Lübke (1861-1936) culminou magistralmente, com as suas obras Grammatik der romanischen Sprachen (1890-1902, 4 vols.) e Romanisches Etymologisches Wörterbuch (1911-1920), o edifício científico alicerçado por Friedrich Diez cerca de meio século antes. Foi no âmbito da filologia românica que ocorreram a criação da dialectologia, da geografia linguística, da metodologia das «Palavras e Coisas» (Wörter und Sachen) e da estilística idealista. Para além da sua generalizada aceitação nos meios universitários e académicos, nas sociedades científicas e culturais, a filologia românica exerceu uma forte influência de natureza social e política, situação que lhe acarretou dúbias hipotecas ideológico-doutrinárias, mas que contribuiu para a sua irradiação e para o seu prestígio. ${ }^{8}$

Com efeito, a filologia, quer a filologia clássica, quer a filologia germânica, quer a filologia românica, foi uma disciplina imperial ao longo da segunda metade do século XIX e das primeiras décadas do século XX. O testemunho de Ernest Renan a este respeito é particularmente elucidativo: na sua obra L'avenir de la science, publicada em 1890 mas escrita em 1848, Renan considera a filologia, estreitamente ligada à crítica e à exegese dos textos, como um dos elementos essenciais do mundo moderno, concebendo-a como a «ciência exacta» das coisas

${ }^{8}$ Esta aura extracientífica foi ainda mais poderosa relativamente à filologia germânica, pois que, como sublinha Gumbrecht, «during the last decades of the 19th century, society and government in Germany quite consciouly required and supported through Germanistik the pattern of national structures of identity» (cf. Hans Ulrich Gumbrecht, op. cit., p. 30). 
do espírito e como o conhecimento correspondente, no plano das «ciências da humanidade», à física e à química no plano da «ciência filosófica dos corpos». Em particular, a filologia foi para Renan uma ciência fundamental nas suas investigações sobre as origens históricas do Cristianismo. De tal modo a filologia se converteu numa ciência de vanguarda e de moda, que Ramalho Ortigão não se esqueceu de a mencionar entre os saberes predilectos de Fradique Mendes: «[Fradique] faz armas como o cavaleiro de Saint-Georges, possui as noções mais novas e as mais certas sobre Física, sobre Astronomia, sobre Filologia e sobre Metafísica».

A «ciência nova» proclamada por Vico encontrava na filologia, em especial na filologia românica e na filologia germânica, a sua realização exemplar, em conjugação com a história, a história literária, a história do direito, a etnologia, a mitografia, a arqueologia, o folclore, etc. As nações europeias, quer as nações-estados, quer as nações em busca da sua constituição como estados, encontraram na filologia uma poderosa matriz disciplinar que fundamentava e iluminava a sua identidade nacional, as suas raízes e origens, os seus heróis e os seus ideais e que, por isso mesmo, devia desempenhar uma função central na Escola. As relíquias dos mais antigos textos escritos nas línguas românicas ou proto-românicas, os primitivos cancioneiros, as velhas crónicas, os poemas épicos medievais, as lendas hagiográficas, os dramas litúrgicos, os romances alegóricos, etc., para além do seu valor intrínseco como objectos de estudo filológico, histórico-literário e linguístico, detinham um valor simbólico com alto significado político: a ressurreição filológica da Idade Média foi um dos pilares do nacionalismo romântico e do nacionalismo tardo-oitocentista.

O Decreto de 9 de Maio de 1911, que criou as Faculdades de Letras das Universidades de Coimbra e de Lisboa, assinalava como finalidades das novas Escolas «o aperfeiçoamento e a expansão da alta cultura intelectual no domínio das ciências filosóficas, filológicas, históricas e geográficas, e a preparação científica para o exercício das profissões que exigem o conhecimento daquelas ciências». Em conformidade com estes objectivos científicos, culturais e pedagógicos, foram criados na Faculdade de Letras da Universidade de Coimbra seis grupos disciplinares, sendo os três primeiros de natureza filológica: $1 .^{\circ}$ grupo, Filologia Clássica; $2{ }^{\circ}$ grupo, Filologia Românica; $3{ }^{\circ}$ Grupo, Filologia 
Germânica. Com um século de atraso em relação à Universidade de Berlim, o Governo da República Portuguesa institucionalizava assim na Universidade de Coimbra as modernas ciências humanas e sociais, que em Lisboa eram já objecto de ensino e investigação no Curso Superior de Letras, Escola em que avultava, na área da filologia, Francisco Adolfo Coelho (1847-1919), «benemérito introdutor da ciência romanística em Portugal», segundo as palavras de Carolina Michaëlis.

No dia 19 de Janeiro de 1912, às três horas da tarde, era recebida com jubilosas e merecidas honras, na Sala Grande dos Actos da Universidade de Coimbra, a nova professora ordinária de Filologia Portuguesa e depois de Filologia Românica, Carolina Michaëlis de Vasconcelos (1851-1925), que fora nomeada professora ordinária da Faculdade de Letras de Lisboa, na qual não chegou a exercer, e que tinha sido transferida, a seu pedido, para a Faculdade de Letras de Coimbra. Perante o Reitor da Universidade, Doutor Mendes dos Remédios (1867-1932), o Director da Faculdade de Letras, Doutor António de Vasconcelos (1860-1941), outros professores e muitos estudantes, Carolina Michaëlis assumiu solenemente o compromisso de continuar e aprofundar, segundo as suas próprias palavras, «a missão literária» que há longos anos vinha desempenhando e dedicou a Coimbra - Dona Carolina não resistiu a cognominá-la «Lusa Atenas» ... - palavras de rendida homenagem: «esta terra cheia de magia, cercada de naturais encantos que fazem dela um paraíso para os poetas e um abrigo delicioso para o estudo - terra cercada também do prestígio de recordações históricas que venero».

Carolina Michaëlis de Vasconcelos, nas memoráveis lições que ministrou no Curso de Filologia Portuguesa, no seguimento do programa até então assegurado pelo Doutor António de Vasconcelos -

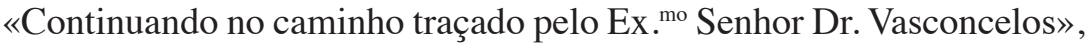
lê-se na abertura da Lição I -, deixou bem claro que a sua orientação metodológica se situava na área da Wortphilologie, da filologia da palavra, da língua e da literatura, e não no campo desmesuradamente polimático da Sachphilologie, a filologia da coisa, a filologia do conhecimento do conhecido (cognitio cogniti), como programaticamente fora advogado por Friedrich Wolf e por August Boeckh e pelos seus discípulos e mais tardiamente fora proclamado por Nietzsche e por Erwin Rohde e ainda hoje é acerrimamente defendido por filólogos e pensadores que reivindicam o legado de Nietzsche e que menosprezam os filólogos que denominam os «filólogos de etiqueta», a começar por 
Wilamowitz-Moellendorf (1848-1931), o princeps philologorum da filologia clássica. ${ }^{9}$

Carolina Michaëlis formula assim o seu conceito de filologia portuguesa: «é o estudo científico, histórico e comparado da língua nacional em toda a sua amplitude, não só quanto à gramática (fonética, morfologia, sintaxe) e quanto à etimologia, semasiologia, etc., mas também como órgão da literatura e como manifestação do espírito nacional». ${ }^{10}$ Estamos perante uma definição paradigmática da filologia portuguesa, subdivisão ou ramo da filologia românica, como Wortphilologie, articulando indissociavelmente o estudo da língua e o estudo da literatura e deixando aberto o horizonte, em consonância com o historicismo romântico, para reflexões ou especulações acerca

${ }^{9}$ Veja-se, e.g., Manuel Crespillo, La idea del límite en filología, Málaga, 1999, obra que constituiu um requisitório veemente contra a Wortphilologie, depreciativamente denominada «filisteofilología».

${ }^{10}$ Carolina Michaëlis de Vasconcelos, op. cit., p. 156. Na Lição I das prelecções de filologia portuguesa feitas ao curso de 1912/1913, afirma Carolina Michaëlis: «Bopp, Grimm, Diez e todos os sucessores abstraíram da literatura propriamente dita - só trataram de línguas: para esse fim, claro que utilizaram textos arcaicos, mas apenas para documentação das formas que explicavam. A divisão fez-se porque em todas as nações cultas a literatura é campo tão vasto e fecundo que exige uma cultura independente. Só em obras enciclopédicas, divididas entre muitos obreiros, é que se reunem línguas e literaturas», como acontecia no Grundriss de Gröber (cf.op.cit.,pp.133-134).Estas afirmações,querelevamdos princípiosdadiferenciação e autonomização dos saberes disciplinares - princípios progressivamente aceites e praticados nas Universidades do século XIX -, não são inteiramente exactas, pois que Jacob Grimm, para além do interesse que lhe suscitaram os contos para a infância, editou em 1815 uma Silva de romances viejos e Diez publicou em 1818 a colectânea Altspanischen Romanzen, com a sua tradução de romances medievais espanhóis; em 1826, saiu à luz a sua obra Die Poesie der Troubadours e em 1829 foi a vez de dar à estampa o livro Leben und Werken der Troubadours, dois marcos cimeiros dos modernos estudos sobre a poesia dos trovadores provençais e sobre as origens da lírica europeia. É verdade que Diez se afastou depois dos estudos literários, mas em 1862, segundo o testemunho do seu discípulo Gaston Paris, confessava que o seu gosto teria sido o cultivo da história literária e não o da gramática (cf. Ulrich Wyss, «Jacob Grimm et la France», Michel Espagne e Michael Werner (eds.), Philologiques. I. Contribution à l'histoire des disciplines littéraires en France et en Allemagne au XIX ${ }^{\mathrm{èm}}$ siècle, Paris, 1990, p. 63).Gaston Paris, o grande mestre da filologia românica em França, demonstrou inequivocamente com a sua obra a inverdade daquelas afirmações de Carolina Michaëlis. 
da relação da língua e da literatura com a entidade denominada «espírito nacional».

Em contraste com a sua definição de filologia portuguesa, analisa Carolina Michaëlis de Vasconcelos a concepção de «filologia nacional» exposta por Adolfo Coelho na sua obra A língua portuguesa (1880), na qual o professor do Curso Superior de Letras restringia o conceito de filologia ao estudo dos textos literários e considerava o estudo da língua como disciplina ou ciência à parte, a que dava o nome de glotologia. Por outro lado, Carolina Michaëlis analisa a terminologia e os conceitos utilizados por Leite de Vasconcelos (1858-1941) que, em deliberada oposição a Adolfo Coelho, denominou filologia e não glotologia o estudo científico da língua e que, cultivando em particular a dialectologia e a gramática histórica e comparativa, praticamente excluiu da filologia a literatura. Na sua definição de filologia, observa Carolina Michaëlis com a severidade ácida que lhe é peculiar, manifesta Leite de Vasconcelos «a sua pouca afeição ou inclinação natural para investigações literárias, generalidades, filosofias, valores estéticos e éticos». Juízo impiedoso que devasta o poeta de Baladas do Ocidente (!885) e de Nuvens (1898)...

Nas definições, nos termos e conceitos acabados de referir, encontram-se delineados, sob forma explícita e implícita, os problemas centrais da filologia em geral e da filologia românica, em particular.

Primeiramente, o problema das relações entre o estudo da língua e o estudo da literatura. A solução ortodoxa, digamos assim, proposta por Carolina Michaëlis no quadro da Wortphilologie oitocentista, deixou de ser aceitável epistemológica e metodologicamente após Saussure, Bloomfield, a glosemática, o estruturalismo, o gerativismo, etc. A proposta terminológica e conceptual de Leite de Vasconcelos era radicalmente inviável depois da condenação exarada por Saussure e por Bloomfield relativamente ao termo e ao conceito de filologia.

Com efeito, a constituição da linguística como ciência autónoma, não subsumível na filologia, é um fenómeno irreversível desde as primeiras décadas do século XX e determinou a alteração do paradigma filológico hegemonicamente estabelecido ao longo do século XIX. O termo "linguística" foi utilizado, em 1808, por Johann-Severin Vater (1771-1826) para designar a disciplina que analisa «as propriedades das diferentes línguas, estabelece a sua classificação e, a partir daí, 
tira conclusões sobre a sua genealogia e o seu parentesco». ${ }^{11}$ Como se pode deduzir, uma disciplina que se inscrevia por conseguinte no modelo histórico-comparativo do estudo das línguas e que, por isso mesmo, era entendida como equivalente, no plano da investigação das línguas, à filologia comparada e à gramática comparada e como contraposta à gramática e à gramática geral, as quais se ocupavam, nas palavras de Jean-Claude Milner, de propriedades das línguas que são constantes e independentes de quem profere a língua, dos seus eventuais destinatários e das circunstâncias da proferição. ${ }^{12}$ Aliás, no âmbito da própria filologia clássica a gramática comparada configurou-se com frequência como área relativamente autónoma centrada sobre fenómenos linguísticos, sem articulação com os textos literários. No âmbito da filologia românica, um filólogo eminente, aluno de Diez, como Hugo Schuchardt (1842-1927), autor da obra pioneira Das Vokalismus des Vulgärlateins (3 vols., 1866-1868), dedicou-se exclusivamente ao estudo de matérias linguísticas. O mesmo se pode afirmar de W. Meyer-Lübke. A geografia linguística, tão importante para o estudo da dialectologia, teve relações nulas ou muito exíguas com a literatura (salvo, pontualmente, com a chamada literatura regionalista). G.I.Ascoli, a quem se devem trabalhos fundamentais para o desenvolvimento da dialectologia românica e que exerceu uma forte influência na política universitária italiana do seu tempo, defendeu que a filologia românica devia ser entendida como disciplina predominantemente ou mesmo exclusivamente linguística, centrada nos estudos dialectológicos e etimológicos. ${ }^{13}$ Gustav Körting, na sua já citada Encyclopädie und Methodologie der romanischen Philologie (1884), entende que a linguística estuda a língua em si mesma e por si mesma, ao passo que a filologia é uma ciência da linguagem «não no sentido próprio e restrito do termo», visto que o seu estudo da língua é instrumental para a sua finalidade: «o conhecimento da vida do espírito». ${ }^{14}$

${ }^{11}$ Cf.Sylvain Auroux (ed.), op. cit., p. 11.

${ }^{12}$ Jean-Claude Milner, Introduction à une science du langage, Paris, 1989, p. 44 .

${ }^{13}$ Veja-se Guido Lucchini, Le origini della scuola storica. Storia letteraria e filologia in Italia (1866-1883), Bologna, 1990, pp. 177-178 e 188.

${ }^{14} \mathrm{Cf}$ Michael Werner, «A propos de l'évolution historique des philologies modernes. L'exemple de la philologie romane en Alemagne et en France», Michel Espagne e Michael Werner (eds.), op.cit., p. 163. 
A dinâmica de autonomização cientifico-disciplinar da linguística alcançou o seu ponto de não retorno quando o Cours de linguistique générale (1916) de Ferdinand de Saussure, na sua primeira página, exautorou epistemológica e metodologicamente a filologia oitocentista, sublinhando a heterogeneidade do seu objecto de estudo e apontando a sua grande limitação: «elle s'attache trop servilement à la langue écrite et oublie la langue vivante; d'ailleurs c'est l'antiquité grecque et latine qui l'absorbe presque complètement».

São inúteis e contraproducentes as objurgatórias dos raros filólogos nietzschianos ainda existentes - os «filólogos do espírito», como gostam de se autodenominar - contra a língua comum, contra a língua oral, contra a fonologia, contra a sociolinguística, contra a pragmática linguística, contra a análise do discurso, etc., etc. O problema tem de ser perspectivado e equacionado de outro modo: evitar que a linguística se distancie irremediavelmente do estudo dos textos literários e contribuir, em contrapartida, como tenho defendido, para o estabelecimento de uma nova interdisciplinaridade entre linguística e análise literária lato sensu, sem prejuízo da autonomia dos dois campos disciplinares e para benefício de ambos. A história da língua, a morfossintaxe, a semântica e a lexicologia são indispensáveis à ecdótica e à hermenêutica dos textos literários e a linguística do texto, a estilística da língua, a pragmática e a análise do discurso são indispensáveis para o estudo da estilística do texto, da comunicação literária, da antropologia do discurso literário, etc. Os textos literários são criados, são produzidos, são feitos - um fazer que reactiva o helénico poiein originário presente em poesia, poema e poeta - na sua textura com materialidades verbais e por isso a literatura mantém com a língua uma relação irrasurável. Este facto não obriga os linguistas a ocuparem-se do estudo da literatura, mas aconselha ou obriga os teorizadores e os historiadores da literatura, os especialistas de ecdótica e de hermenêutica literária, a conhecerem com rigor as áreas da linguística pertinentes para as suas investigações. Os linguistas não podem, porém, desconhecer quanto a energeia das línguas deve aos escritores e aos textos literários, como Eugenio Coseriu reafirmou num dos seus últimos ensaios recentemente publicado: «El sentido se da sólo en los discursos, pero en todos los discursos, no sólo en los literarios. Con todo, el texto literario ocupa a este respecto una posición privilegiada, ya que la poesía (la «literatura» como arte) es el lugar de la plenitud funcional del lenguaje: del máximo despliegue 
de sus posibilidades». ${ }^{15}$ Do meu ponto de vista, a filosofia da linguagem deverá desempenhar nesta interdisciplinaridade um insubstituível papel de disciplina mediadora.

Por outro lado, é indispensável, embora penoso, reconhecer que a filologia românica, como a filologia em geral, que foi uma disciplina moderna, inovadora e influente académica, cultural e socialmente nas primeiras décadas do século XIX, se foi tornando uma disciplina esterilmente erudita, que confundiu o rigor do conhecimento científico com a acumulação de factos, acantonada na descrição e análise de estádios antigos das línguas, insensível aos valores estéticos e refractária à modernidade tanto da literatura como da teoria e da crítica literárias. Embora com diferenças de país para país, a filologia românica tendeu a confinar-se redutoramente ao estudo das línguas e das literaturas românicas medievais. Um manual bem informado e relativamente recente como a Nuova introduzione alla filologia romanza de Lorenzo Renzi informa que, na Itália, a filologia românica «riguarda de un lato lo studio della genesi delle lingue romanze a partire del loro distaccarsi del latino, e d'altro lato lo studio delle letterature romanze medievali». ${ }^{16}$ Felizmente, desmentindo com a sua obra tão restritiva formulação, egrégios filólogos italianos da segunda metade do século XX, como Gianfranco Contini, Cesare Segre, Ezio Raimondi, D'Arco Silvio Avalle, Maria Corti, etc., foram nas suas teorias e nas suas práticas investigadores que não se confinaram ao estudo das línguas e das literaturas medievais, que manifestaram uma consciência muito aguda das dimensões e implicações estéticas dos textos literários, que valorizaram a modernidade e a vanguarda literárias, que harmonizaram e enriqueceram admiravelmente o seu labor de filólogos com as mais recentes e inovadoras orientações dos estudos literários.

Também a tradição da filologia românica na Faculdade de Letras de Coimbra se afasta da formulação de Lorenzo Renzi atrás citada. Carolina Michaëlis de Vasconcelos, a sua referência matricial, sendo a insigne medievalista que estudou e editou $O$ Cancioneiro da Ajuda, foi também a magistral filóloga que editou as Poesias de Francisco de Sá

\footnotetext{
${ }^{15}$ Eugenio Coseriu e Óscar Loureda Lamas, Lenguaje y discurso, Pamplona, 2006, p.58.

${ }^{16}$ Lorenzo Renzi, Nuova introduzione alla filologia romanza, Bologna, 1985, p.17.
} 
de Miranda, que tão valiosos contributos carreou para o estabelecimento do cânone da lírica de Camões e que muito se interessou por escritores seus contemporâneos como João de Deus, Guerra Junqueiro e Trindade Coelho. A tese de doutoramento de Costa Pimpão, discutida na Sala dos Capelos em Dezembro de 1943, ocupa-se de um escritor, falecido havia poucos anos, que é uma das vozes mais complexas da nossa modernidade estético-literária - Fialho de Almeida. Como evidenciam vários ensaios coligidos nos seus volumes Gente Grada (1952) e Escritos diversos (1972), Costa Pimpão estudou outros escritores modernos como Almeida Garrett, Eça de Queirós e Antero de Quental. Na geração posterior a Costa Pimpão, que foi um mestre liberal no modo como orientou os seus assistentes, Ofélia Paiva Monteiro é a garrettiana distinta que todos admiramos e Aníbal Pinto de Castro consagrou a sua rara capacidade de investigador sobretudo a Camões, a Vieira e a Camilo. Só Aida Fernanda Dias foi a excepção de uma notável filóloga medievalista. Eu próprio tenho percorrido múltiplos caminhos que têm como estrelas polares Camões, a modernidade literária e esse mar sem fim que é a teoria literária. Tão nocivo para a filologia românica é o seu confinamento à literatura medieval como é o seu esquecimento da literatura medieval.

Para além desta imagem negativa da filologia como saber de antiquários e de aborrecidos eruditos, a filologia foi também vítima de fortes resistências e reservas ideologicamente contaminadas. Em França, por exemplo, país onde os conceitos de «belas letras» e de «bom gosto» conformaram e fecundaram durante longo tempo uma requintada cultura literária, a filologia românica, de procedência alemã, elaborada pioneiramente por professores e investigadores alemães, foi julgada suspeitosamente por muitos intelectuais, apesar da elevada qualidade do labor científico e cultural de romanistas como Gaston Paris, Paul Meyer e Joseph Bédier. Em 1879, Ferdinand Brunetière, influente homem de letras, denunciou «os efeitos nefastos da filologia românica sobre o gosto francês, entregue à barbárie tudesca». ${ }^{17} \mathrm{Na}$ mesma linha de pensamento, sob o pseudónimo de Agathon, Henri Massis e Alfred de Tarde publicaram em 1911 um violento libelo contra a filologia como disciplina emblemática da ciência alemã, considerando

\footnotetext{
${ }^{17}$ Apud Michael Werner, op. cit.,p. 176.
} 
que o seu triunfo na Sorbonne, em prejuízo das «ideias gerais», das «letras puras» e do «gosto literário» representativos da tradição francesa, era mais uma consequência calamitosa da derrota francesa na guerra franco-prussiana de 1870: «Ah! Le puissant moyen d'expansion intellectuelle qu'une victoire! Nul ne songeait à mettre en doute que, le sort des armes leur ayantété favorable,c'étaient les procédés de culture, l'enseignement, le génie même des Allemands qui avaient eu raison des nôtres. Et la philologie germanique fut considérée comme un agent de force nationale». ${ }^{18} \mathrm{O}$ próprio conceito de Romania foi considerado em França, algumas vezes, como uma capciosa invenção germânica para diluir a língua e a literatura francesas num todo transnacional. Deve ser salientado, todavia, que Gaston Paris, um filólogo de grande envergadura intelectual e ética, se esforçou reiteradamente para depurar de preconceitos ideológico-políticos a filologia românica, tanto em relação a supostas hipotecas ao nacionalismo alemão como em relação a eventuais e perigosas revindictas do nacionalismo francês. ${ }^{19}$

$\mathrm{Na}$ Inglaterra vitoriana, a apologia da Altertumswissenschaft, levada a cabo por Matthew Arnold como meio de cultivar a classe média, teve efeitos benéficos no contributo da filologia para a institucionalização escolar dos estudos literários, mas a deriva dos estudos filológicos para domínios ambíguos da etnologia e para o campo de línguas arcaicas, extintas ou em extinção, fez com que a ciência filológica fosse considerada como uma ameaça aos valores morais, espirituais e culturais que a literatura devia incutir. Uma súmula representativa desta reacção antifilológica, dirigida, sublinhe-se, contra o desvirtuamento da filologia, encontra-se exposta no manifesto de Hiram Corson, director do Departamento de Inglês da Universidade de Cornell, intitulado The aims of literary study (1895), no qual é atacada a «German literary and philological scholarship» como um grande obstáculo à verdadeira e mais elevada cultura literária e como uma degenerescência que se manifesta numa «piddling analysis which has no end but itself». ${ }^{20}$

\footnotetext{
${ }^{18}$ Agathon, L'esprit de la nouvelle Sorbonne, Paris,1911, p. 12.

${ }^{19}$ Sobre a personalidade e a obra de Gaston Paris, vide duas obras fundamentais: Ursula Bähler, Gaston Paris et la philologie romane, Genève, 2004; Michel Zink, Le Moyen Âge de Gaston Paris, Paris, 2004.

${ }^{20} \mathrm{Cf}$. Gerald Graff, Professional literature. An institutional history, Chicago-London, 1987, pp. 47-48.
} 
Após a I guerra mundial, com muitas chagas a sangrar nos vários países europeus e muitos orgulhos feridos, «it was possible to smear classical philology as a form of ponderous Teutonic nonsense with which no self-respecting Englishman should be caught associating»,para usar as palavras, impregnadas de humor irlandês, de Terry Eagleton. ${ }^{21}$

No museu imaginário que vos convidei a percorrer, à medida que a cronologia avança, multiplicam-se e adensam-se as penumbras, as fissuras, as erosões e as teias de aranha, até se chegar às inscrições tanatográficas lavradas por Ferdinand de Saussure no Cours de linguistique générale (1916) e por Leonard Bloomfield em Language (1933).

Nas Universidades portuguesas, a «reforma Leite Pinto» manteve a designação filológica dos cursos de Licenciatura, mas eliminou as designações filológicas das disciplinas; uma mini-reforma de Veiga Simão acabou com o doutoramento em Filologia Românica e noutras Filologias; a «reforma Cardia» elidiu pura e simplesmente, em todas as áreas e matérias curriculares, o nome da disciplina imperial de Wilhelm von Humboldt. Erros próprios, mudanças dos tempos, ambições concertadas de outras disciplinas, preconceitos, como se viu, de ordem ideológica, conjuraram-se no declínio e na queda da filologia.

Todavia, no vazio assim gerado, há uma necessidade que não pode ser menosprezada e esquecida e que tem de obter uma resposta adequada, em termos institucionais, na investigação e no ensino universitários: a necessidade de restaurar e conservar na sua autenticidade originária, aliando estreitamente a ecdótica e a hermenêutica, os textos escritos em cada língua, em especial os textos literários lato sensu, que representam a memória futurante dos povos. A fragilidade e a friabilidade dos textos, tanto antigos como modernos, tanto manuscritos como impressos, são a fragilidade e a friabilidade do próprio homem. Não é possível cultivar a filologia fazendo economia da hermenêutica, com a sua fundamental componente estética, ${ }^{22}$ e não é possível praticar com rigor a hermenêutica dos textos sem curar da sua própria materialidade, ou seja,

${ }^{21}$ Terry Eagleton, Literary theory. An introduction, Oxford, ${ }^{2} 1996$, p. 26.

${ }^{22}$ Veja-se Hans Ulrich Gumbrecht, The powers of philology. Dynamics of textual scholarship, Urbana-Chicago, 2003, pp. 2 ss. 
sem o fundamento irrasurável da filologia, enriquecida nas últimas décadas com os contributos da variantística e da genética textuais. ${ }^{23}$

Como já escrevi, só uma filologia pós-imperial, tendo entendido as lições do seu banimento, aberta à modernidade sob todos os pontos de vista, em profunda articulação com a linguística, a hermenêutica, a teoria da literatura e a literatura comparada, pode dar resposta àquela necessidade e àquele vazio.

O «inverno», nos corsi e ricorsi da história, das culturas e das instituições, visionados e preditos pelo fundador da scienza nuova, pode dar lugar a uma «primavera» nova...

${ }^{23}$ Sobre a hermenêutica material, veja-se Peter Szondi, Introducción a la hermenéutica literaria, Madrid, 2006, com a excelente introdução de José Manuel Cuesta Abad intitulada «Lectio stricta:La hermenéutica material de Peter Szondi». Veja-se também a proposta de François Rastier, Arts et sciences du texte, Paris, 2001, cap. IV: «Herméneutique matérielle». Sobre hermenêutica e crítica textual, dedicando atenção à variantística e à genética textuais, veja-se Cesare Segre, Ritorno alla critica, Torino, 2001, cap. II. 